\title{
Letter to the editor: no increased febrile neutropenia risk to cancer patients receiving lipegfilgrastim-correction of a systematic review and meta-analysis of randomized controlled trials with G-CSF
}

\author{
W. Lehmacher ${ }^{1}$ - M. Klasser $^{2}$ - A. Duering ${ }^{3}$
}

Received: 18 December 2015 / Accepted: 1 February 2016/Published online: 10 February 2016

(C) The Author(s) 2016. This article is published with open access at Springerlink.com

\section{Reason}

Wang et al. recently published a systematic review and metaanalysis on the impact of primary prophylaxis (PP) with granulocyte colony-stimulating factors (G-CSF) on febrile neutropenia (FN) during chemotherapy [1]. In the article, the authors state that "over all chemotherapy cycles, there was a numerical but statistically nonsignificant increase in the FN risk for lipegfilgrastim PP versus pegfilgrastim PP" four times.

We would like to state that in our view, this claim is not justified for the following three major reasons:

1. It is based on an indirect and mixed treatment comparisons although direct evidence is available from two recent head-to-head randomized controlled trials (RCTs) showing a compatible risk.

2. A non-significant result is not conclusive and does not show evidence for the existence of an increase.

3. The indirect comparison has a poor validity because of missing homogeneity, similarity, and consistency.

M. Klasser

Manfred.Klasser@gwd-consult.de

A. Duering

Andreas.Duering@TEVA.DE

1 Institute for Medical Statistics, Information and Epidemiology, Cologne University, Kerpener Str. 62, 50937 Cologne, Germany

2 GWD Consult Contract Research, Mozartstrasse 2-4, 63165 Muehlheim am Main, Germany

3 TEVA GmbH, Charlottenstraße 59, 10117 Berlin, Germany

\section{Contradiction}

Ad 1) The study aimed to assess the G-CSF products administered as primary prophylaxis to cancer patients receiving myelosuppressive chemotherapy. A systematic literature review identified 27 publications (1990 to 2013) representing 30 randomized, controlled trials evaluating primary prophylaxis $(\mathrm{PP})$ with filgrastim, pegfilgrastim, lenograstim, or lipegfilgrastim in adults receiving myelosuppressive chemotherapy for solid tumors or nonHodgkin lymphoma (see Fig. 1). Direct, indirect, and mixed treatment comparison (MTC) were used to estimate the odds ratio $(\mathrm{OR})$ of febrile neutropenia $(\mathrm{FN})$ during cycle 1 and all cycles of chemotherapy combined without adjusting for differences in relative dose intensity (RDI) between study treatment arms.

It becomes apparent from Fig. 1 that there were two head-to-head studies comparing directly lipegfilgrastim with pegfilgrastim $[2,3]$ including a total of 306 patients.

The results of the meta-analysis for this direct comparison are shown in Fig. 2; seven events of FN occurred in each treatment group. The odds ratio for the "combined view" is 0.98 .

Table 1 shows the posterior odds ratios for $\mathrm{FN}$ from all cycles with and without the assumption of consistency.

The OR for the direct comparison is 1.00 (indicating equal risks for $\mathrm{FN}$ by lipegfilgrastim and pegfilgrastim). The result of the "indirect comparison" is completely different, $\mathrm{OR}=2.00$, seemingly indicating an "increased" risk for FN by lipegfilgrastim. The result of the combination of direct and indirect comparison (MTC) is between the results of direct and indirect comparison $(\mathrm{OR}=1.39)$. 
Fig. 1 Overview of data from RCTs on G-CSF PP included in meta-analysis

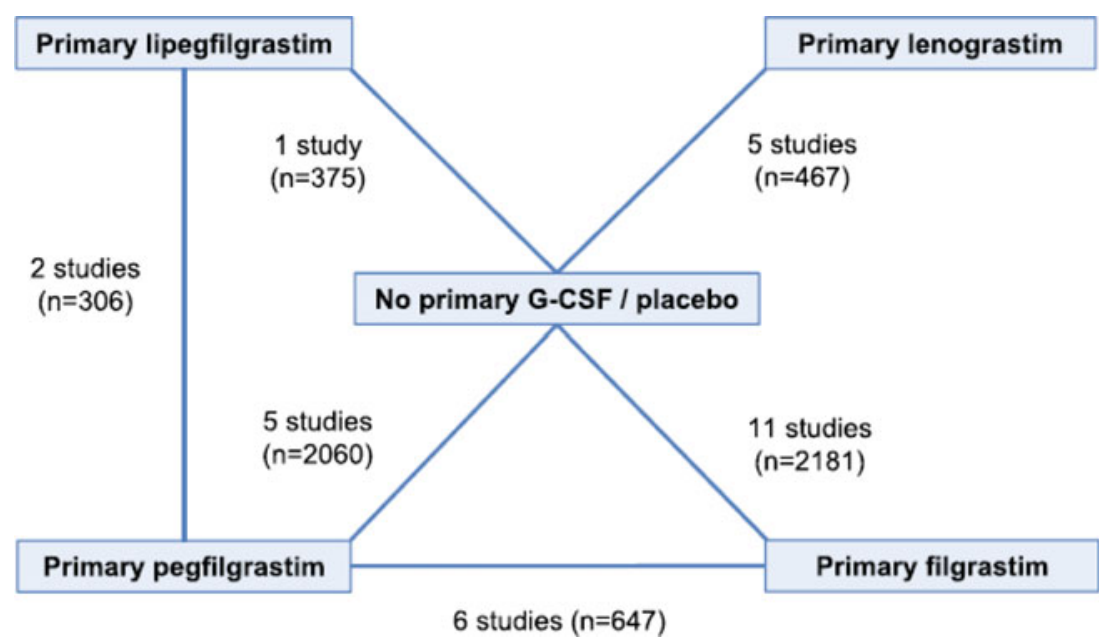

Which approach is providing the best evidence?

The Cochrane Handbook for Systematic Reviews of Interventions [4] states: "In situations when both direct and indirect comparisons are available in a review, then unless there are design flaps in the head-to-head trials, the two approaches should be considered separately and the direct comparison should take precedence as a basis of forming conclusions."

Leading institutions for health technology assessment (HTA) such as the Canadian Agency for Drugs and Technologies in Health (CADTH) [5], the National Institute for Health and Clinical Excellence (NICE), London [6] and the German Institute for Quality and Efficiency in Health Care (IQWiG), and Cologne [7] have a clear recommendation for this situation:

- They have a preference for data from head-to-head RCTs.

- Evidence from mixed treatment analyses may be presented if it is considered to add information.

- If data from head-to-head RCTs are not available, indirect treatment comparison methods may be used.

Many methodological questions for MTCs still remain to be answered [8]. In a current review,
Song et al. [9] describe that significant differences between results from indirect and direct comparisons occur more frequently than previously assumed. Due to the high risk of biased results and the numerous unresolved methodological problems, in general, no certain proof of benefit of a medical intervention can currently be inferred from results of indirect comparisons.

Therefore, claiming a non-significant numerical higher risk for $\mathrm{FN}$ for lipegfilgrastim compared to pegfilgrastim is not sustainable. There were a total of 7:7 events of FN in both head-to-head studies together, but an indirect OR of 2.0 indicates that the application of inconsistent indirect or mixed methods is not only unnecessary but leads to potentially biased risk estimates.

Ad 2) Results from clinical studies may be conclusive only if hypothesis testing leads to statistically significant results. Therefore, it is impossible to claim a "numerical difference" in favor of a group without statistical significance. For example, in the head-to-head studies against pegfilgrastim, lipegfilgrastim showed "numerical but not statistically significant" superiority in several other

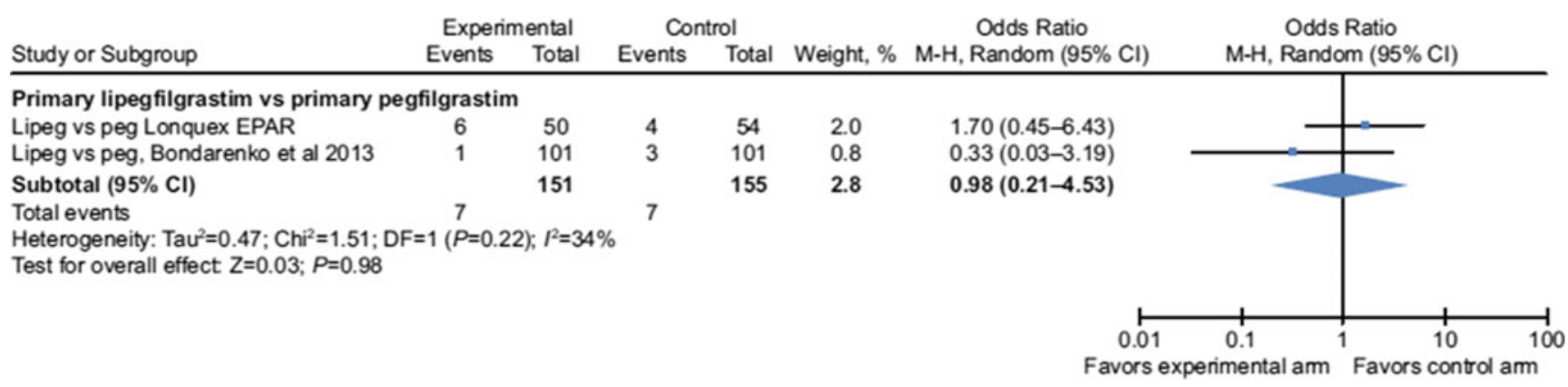

Fig. 2 Meta-analysis comparing directly lipegfilgrastim with pegfilgrastim 
Table 1 Posterior odds ratios for febrile neutropenia from all cycles with and without the assumption of consistency for lipegfilgrastim vs. pegfilgrastim

\begin{tabular}{lllll}
\hline $\begin{array}{l}\text { Treatment } \\
\text { contrast }\end{array}$ & $\begin{array}{l}\text { Direct OR } \\
(95 \% \mathrm{CI})\end{array}$ & $\begin{array}{l}\text { Indirect OR } \\
(95 \% \mathrm{CI})\end{array}$ & $p$ value & $\begin{array}{l}\text { Combined } \\
(\mathrm{MTC}) \mathrm{OR} \\
(95 \% \mathrm{CI})\end{array}$ \\
\hline $\begin{array}{l}\text { Lipegfilgrastim } \\
\text { vs. pegfilgrastim }\end{array}$ & $1.00(0.26-3.79)$ & $2.00(0.47-8.11)$ & 0.76 & $1.39(0.54-3.50)$ \\
\hline
\end{tabular}

efficacy parameters. So far, such advantages have not been claimed, due to statistical non-significance.

Ad 3) The indirect comparison itself lacks validity: the metaanalysis of five studies comparing pegfilgrastim vs. placebo shows a strong heterogeneity due to the oldest study (Vogel et al. [10]). The meta-analysis of the pegfilgrastim studies shows a total event rate of $15.1 \%$ in the control group, whereas the lipegfilgrastim studies have a total event rate of $8 \%$. This shows a strong dissimilarity in the types of patients included which could be the reason for the inconsistency between direct and indirect comparison.

\section{Conclusion}

It is not justified to claim a numerical difference in favor of a specific treatment based on non-significant study results. The result of a mixed treatment comparison with poor validity is less reliable than the evidence from available direct comparison. Thus, the FN risk for lipegfilgrastim PP relative to pegfilgrastim PP is comparable.

\section{Compliance with ethical standards}

Conflict of interest Professor Walter Lehmacher was acting on Data Safety and Monitoring Boards and Advisory Boards and gave lectures and received research grants from Bayer, Boehringer Ingelheim, Biotronik, Fresenius, Janssen, Novartis, Sanofi, and Schwabe.

Manfred Klasser is an independent Clinical Research Consultant for the pharmaceutical industry.

Andreas Duering is an employee of TEVA GmbH.
Open Access This article is distributed under the terms of the Creative Commons Attribution-NonCommercial 4.0 International License (http:// creativecommons.org/licenses/by-nc/4.0/), which permits any noncommercial use, distribution, and reproduction in any medium, provided you give appropriate credit to the original author(s) and the source, provide a link to the Creative Commons license, and indicate if changes were made.

\section{References}

1. Wang L, Baser O, Kutikova L, Page J, Barron R (2015) The impact of primary prophylaxis with granulocyte colony-stimulating factors on febrile neutropenia during chemotherapy: a systematic review and meta-analysis of randomized controlled trials. Support Care Cancer 23(11):3131-3140

2. EPAR assessment report on Lonquex. EMA/371234/2013 of May 30, 2013

3. Bondarenko I, Gladkov O, Elsasser R, Buchner A, Bias P (2013) Efficacy and safety of lipegfilgrastim versus pegfilgrastim: a randomized, multicenter, active-control phase 3 trial in patients with breast cancer receiving doxorubicin/docetaxel chemotherapy. BMC Cancer 13:386

4. Higgins J, Greene S (eds) The Cochrane handbook for systematic reviews of interventions. Version 5.1.0; March 2011. http:// handbook.cochrane.org/front page.htm

5. CADTH (2006) Guidelines for the economic evaluation of health technologies. http://www.cadth.ca/media/pdf/186 EconomicGuidelines_e.pdf

6. NICE (2008) Evidence Synthesis. Guide to the methods of technology appraisal. National Institute for Health and Clinical Excellence (NICE), London, http://www.nicedsu.org.uk/Evidence-SynthesisTSDseries\%282391675\%29.htm

7. IQWiG (2012) Importance of results from indirect comparisons. Joint Statement from IQWiG, GMDS and IBS-DR. https://www. iqwig.de/download/Joint_Statement_Indirect_Comparisons.pdf

8. Song F, Loke YK, Walsh T et al (2009) Methodological problems in the use of indirect comparisons for evaluating healthcare interventions: a survey of published systematic reviews. BMJ 338:1147

9. Song F, Xiong T, Parekh-Bhurke S, Loke YK, Sutton AJ, Eastwood AJ, Holland R, Chen YF, Glenny AM, Deeks JJ, Altman DG (2011) Inconsistency between direct and indirect comparisons of competing interventions: meta-epidemiological study. BMJ 343:4909

10. Vogel CL, Wojtukiewicz MZ, Carroll RR, Tjulandin SA, BarajasFigueroa LJ, Wiens BL, Neumann TA, Schwartzberg LS (2005) First and subsequent cycle use of pegfilgrastim prevents febrile neutropenia in patients with breast cancer: a multicenter, doubleblind, placebo-controlled phase III study. J Clin Oncol 23:11781184 